\title{
Nutrition policy in Finland
}

\author{
Pirjo Pietinen ${ }^{1, *}$, Satu Männistö ${ }^{1}$, Liisa M Valsta ${ }^{1}$ and Sirpa Sarlio-Lähteenkorva ${ }^{2}$ \\ ${ }^{1}$ National Institute for Health and Welfare, PO Box 30, Fl-00271 Helsinki, Finland: ${ }^{2}$ Ministry of Social Affairs \\ and Health, Helsinki, Finland
}

Submitted 20 July 2009: Accepted 15 March 2010

\begin{abstract}
The present study describes the main actions in Finnish nutrition policy during the past decades. The main actor is the National Nutrition Council, which provides nutritional recommendations and action programmes, and sets up expert groups to solve nutritional problems in the population. The main fortification programmes have been the iodization of table salt, supplementation of selenium to fertilizers and the vitamin D fortification programme. As an example of national legislation, labelling the salt content of foods is described. Finnish nutrition policy is based on a good monitoring system of nutrition and risk factors of chronic diseases, as well as active epidemiological research. However, the authorities have not often taken proposed fiscal measures seriously but have instead considered agricultural and economic policies more important than health policy.
\end{abstract}

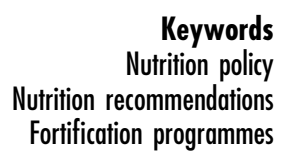

Keywords

utrition recommendations

Fortification programmes
Health promotion, including promotion of healthy diets for all, is seen as increasingly important in political decision-making in Finland. The current government has set up a special policy programme for health promotion, and the contents were adopted as part of the government's strategy document in December 2007 $7^{(1)}$. The objective of this policy programme is to improve the population's state of health and to reduce health inequalities. By tackling the causes behind the major chronic diseases such as poor diets, it is possible to curb the considerable costs arising from health-care services, sick leave and premature retirement. The objectives of the policy programme for health promotion include reinforcing the structures of health promotion, achieving lifestyle changes that contribute to the prevention of public health problems, the development of working and living conditions that promote healthy lifestyle choices, strengthening the basic services of social welfare and health care, the development of new work patterns for health promotion and reinforcing the activities and role of organizations that provide support for health promotion.

The government resolution on development guidelines for health-enhancing physical activity and nutrition was accepted in June 2008 as a part of the policy programme for health promotion ${ }^{(2)}$. This resolution is politically and historically significant since the Finnish government has never previously given any guidelines on nutrition. Moreover, as a part of this initiative, Cabinet ministers are personally committed to promoting health in their own lives and workplaces ${ }^{(3)}$.

The main targets defined by the Government are the promotion of population health and the prevention of diseases so that: (i) the number of people that pursue sufficient physical activities for health benefits increases and the number of people marginalised from physical activity decreases; (ii) the number of people following nutritional recommendations grows through increasing the intake of vegetables, fruits and berries and through decreasing the intake of saturated fat, salt and sugar; (iii) overweight and obesity, as well as other health problems related to nutrition and physical inactivity decrease; and; (iv) dietary and physical activity habits that promote health become more common especially among population groups with the lowest socio-economic status. The resolution includes targets and development guidelines for different age and population groups, everyday environments that promote healthy physical activity and good dietary habits, local decision-making and training of different occupational groups on these agendas as well as in monitoring and utilization of research. Health-enhancing physical activity and healthy diets are promoted by influencing culture, living environment, circumstances, products and structures, ensuring that all population groups have sufficient information and skills for a healthenhancing lifestyle, and encouraging, supporting and guiding individuals and communities, especially the most vulnerable, to help them achieve these objectives.

As a part of the resolution, a concrete plan for the implementation of the different target areas has been drawn up for 2008-2011, i.e. for the term of office of the present government. As part of this implementation work many activities have already started including legal proposals, fiscal tools, education and various action plans. The implementation of the resolution is co-ordinated and 
followed up by the Ministry of Social Affairs and Health, the Ministry of Education and the Ministry of Agriculture and Forestry in their spheres of authority, as well as by the Committee for Health-Enhancing Physical Activity and the National Nutrition Council as advisory bodies.

Promotion of healthy diets and nutrition is also an important part of other current programmes and action plans. Nutrition, especially safeguarding of the quality of school meals and promoting healthy food habits in families, is also an integral part of the government's programme for promoting Finnish food culture. Moreover, in the National Action Plan to Reduce Health Inequalities 2008-2011, there are proposals to address the promotion of healthy dietary habits among lower socio-economic groups. The first proposal is to promote the availability of reasonably priced meals that comply with nutritional recommendations, particularly at small workplaces and among employees required to travel frequently, in accordance with the recommendations of the working group on monitoring and developing mass catering services. This working group will launch an action plan by the end of 2009. The second proposal is to safeguard adequate physical activity and a healthy diet for the most socioeconomically disadvantaged and marginalized individuals according to the Government resolution on healthpromoting nutrition and physical activity ${ }^{(4)}$.

\section{Finnish nutritional recommendations as guidelines for healthy eating}

The latest Finnish nutritional recommendations were issued in 2005 by the National Nutrition Council ${ }^{(5)}$. The council is an expert group appointed by the Ministry of Agriculture and Forestry, and the members are representatives of authorities and stakeholders related to health and nutrition policy, food safety, research, health promotion, food production, trade, consumers and catering services. The council has published nutritional recommendations four times since 1981 .

The Finnish nutritional recommendations are based on the Nordic nutrition recommendations, which were approved in 2004 by the Nordic Council of Ministers ${ }^{(6)}$. The recommendations provide authoritative advice for people (at least 2 years old) on how good dietary habits can promote health and reduce the risk of major dietrelated diseases such as CVD, osteoporosis, obesity, diabetes and dental diseases. The basis for setting recommendations is defined for each individual nutrient using available scientific evidence. The recommendations are valid for an average intake over a longer period of time in the groups of healthy individuals. The nutritional recommendations have been established as a guideline for planning diets for groups, as a basis for teaching and dietary information, for evaluation of dietary intake, and for food and nutrition policy. For the first time, recommendations on physical activity are also included and are stated as at least 30 min physical activity of moderate intensity per day for adults, $60 \mathrm{~min}$ to prevent being overweight and at least $60 \mathrm{~min}$ for children.

Recently, a food-based dietary guideline for consumers has also been published to help people choose foods that meet the recommendations. Furthermore, the guideline includes food plate models to illustrate how to put together a healthy meal from different components. Additional recommendations have been published for specific purposes, such as for catering service, hospitals and nursing homes, prisons, armed forces and for athletes. The most recent recommendations have been concerned with a healthy diet for infants and young children, as well as for pregnant and breast-feeding mothers, and a healthy diet at elementary and other schools (both only available in Finnish). The recommendations for senior citizens and for catering service at hospitals and nursing homes are being revised.

\section{Catering services}

In Finland, we have a long tradition of having lunch outside the home served by catering services for as long as women have generally had full-time jobs ${ }^{(7,8)}$. A third of the population eats at least one meal outside the home daily. In 2005, 769 million meals were served by large-scale catering kitchens, i.e. on average 135 meals per inhabitant per year. Most meals were served at schools (20\%), workplace canteens (15\%) and restaurants and hotels (15\%), whereas day-care centres, staff canteens, old people's homes and hospitals each accounted for about $10 \%$. The well-balanced and healthy meals served by catering services have had a significant impact on improving the diet among Finns over the past decades. A detailed article on this issue can be seen in this supplement ${ }^{(9)}$.

A free school lunch consisting of a hot meal, salad, bread and milk (or water) is served every school day to all Finnish children in primary and secondary schools, as well as in vocational institutes. This over 60-year-old (established in 1948) system for offering school lunch is unique worldwide and a source of national pride. The aim is to promote the students' health, working capacity and good table manners. In addition, university students have had subsidized meals since $1979^{(9)}$.

The recent intervention study showed that $71 \%$ of the seventh and eighth grades secondary-school students ate school lunch every day ${ }^{(10)}$. However, only $25 \%$ of the girls and $30 \%$ of the boys reported having eaten all the components of the school lunch. Only $20 \%$ of daily energy intake was derived from the school lunch, compared to a recommended level of one-third. The school lunch, however, was the healthiest meal that the children ate during the day. The present study also showed that unhealthy snacks should be made less readily available 
on school premises and should be replaced by a larger variety of healthy snack options.

Workplace canteens and restaurants are supported by different tax agreements and subsidies to promote their use among employees ${ }^{(8)}$. However, employees with higher education, and who work at large workplaces use canteens more often than others ${ }^{(11)}$. Employees having lunch at canteens are also more likely to follow nutritional recommendations compared with others ${ }^{(9)}$. In particular, having lunch at the canteen seems to increase the frequency of vegetable and fish consumption. In Finland, workplaces are an important key element in improving health and reducing the risk of chronic diseases among the adult population.

New criteria for assessing nutritional quality of meals have been launched by the Finnish Heart Association. The criteria provide a tool that helps the staff to easily assess fat and salt content of served meals. Furthermore, a newly introduced 'heart symbol' is also used to help guide the customers of workplace canteens to choose healthier meals. Only meals that fulfil the requirements, with recipes that have been accepted by the Finnish Heart Association and the Finnish Diabetes Association, are allowed to be tagged with the heart symbol. In addition, a working group for monitoring and developing mass catering services plans to enlarge the nutritional criteria for procurement contracts of catering services.

\section{The first Finnish beverage recommendations}

The beverage consumption of Finnish people has been fairly moderate, with the exception of alcohol consumption. The variety of beverages on the market has, however, grown rapidly and substantially during the past years. In addition, a decrease in the price of alcohol has increased consumption of alcoholic beverages. The most critical nutritional and health-related factors in beverages are energy, sugars, fats, acidity, caffeine and alcohol. Beverage consumption has been shown to be related to the increasing prevalence of obesity, is possibly connected with an increased risk of certain chronic diseases ${ }^{(12)}$ and seems to jeopardize the improvements in dental health achieved during the past decades in Finland. Increased caffeine consumption through energy and coffee drinks may be related to altered behaviour in children and adolescents ${ }^{(13)}$. Against this background the National Nutrition Council published a report on the role of beverages in nutrition providing expert statements concerning healthy drinking ${ }^{(14)}$. The report was followed by illustrated beverage recommendations for consumers. These were published separately for children/adolescents, adults and the elderly in 2009.

\section{Supplementation of fertilizers with selenium}

Selenium is unevenly distributed in the soil worldwide, and Finland is one of the low selenium regions in the world due to climatic and geochemical reasons. To improve the quality of Finnish foods, animal health and to increase the selenium intake of the population, an official decision was made in 1984 to supplement compound fertilizers with selenium. Practically all fertilizers used in Finland have contained selenium since $1985^{(15)}$.

After the role of selenium in physiology became better understood, several studies were initiated in the late 1970s to study the potential health effects of low selenium intake ${ }^{(16,17)}$. These studies provided evidence of increased risk of CVD and cancer due to low selenium intakes. This information resulted in a great deal of discussions in the Finnish media, and further to dramatic increases in sales of selenium supplements. From the public health point of view this was not a sustainable solution, because selenium intake was distributed extremely unevenly among different population groups. People not taking selenium supplements were still subject to selenium deficiency, while some of those taking supplements in excess were facing a risk of overdosing, as the margin between the daily need and overdose is exceptionally narrow for selenium.

An extensive research programme was launched to study the ways to increase the dietary intake of selenium of the Finnish population. In 1983, the Ministry of Agriculture and Forestry set up a selenium working group to draft a proposal concerning the addition of selenium to general fertilizers and to draw up a research and monitoring plan for observing the impact of the added selenium on the soil, plants, feeds and foodstuffs of plant and animal origin, as well as on the selenium intake of humans and animals.

The average daily selenium intake in the middle of the 1970s, when grain was not imported, was as low as $25 \mu \mathrm{g}$ per person. The selenium supplementation increased the intake substantially, and the highest plateau was reached from 1986 to 1990 , when it was between $110 \mu \mathrm{g}$ and $120 \mu \mathrm{g}$. Since then, the supplementation dose was lowered and the intake level has been $70-80 \mu \mathrm{g}$ in the $2000 \mathrm{~s}^{(15)}$. The present trend in the intake is still decreasing but can still be considered to meet well the recommendations.

The selenium programme has been founded on comprehensive, long-term research and monitoring and measures undertaken based on a large body of data. The addition of selenium to fertilizers in Finland may be considered as an excellent example of good collaboration between companies, researchers and authorities, improving the quality of Finnish food and raising the selenium intake to a sufficient level. However, it is impossible to estimate its potential impact on CVD or cancers.

\section{Vitamin D fortification programme}

Because of poor dietary vitamin D intake and low vitamin D levels in the Finnish population the Ministry of Trade 
and Industry launched a decree on optimal fortification of foods in 2003. Margarines had been fortified with vitamins A and D since the 1950s, but this procedure had too little impact on vitamin $\mathrm{D}$ intake. Hence, all fat spreads were fortified with $10 \mu \mathrm{g}$ vitamin $\mathrm{D}_{3} / 100 \mathrm{~g}$ and fluid milk products with $0.5 \mu \mathrm{g} / 100 \mathrm{ml}$, with the exception of organic milk. The impact was monitored by comparing the vitamin D status and intake in different population groups before and after the new decree ${ }^{(18)}$. Fortification increased vitamin $D$ intake by $1-3 \mu \mathrm{g} / \mathrm{d}$, but the intake was still below the recommended levels among teenage girls, young adults and the elderly, whose recommended level of vitamin $\mathrm{D}$ is higher than for others. Fortification also improved vitamin D levels. Neither the vitamin D intake nor the serum 25-hydroxy-vitamin D concentration has reached levels that are considered excessive. However, $21 \%$ of all and $33 \%$ of non-supplement users still had inadequate vitamin D status in winter (below $50 \mathrm{nmol} / \mathrm{l})$. Among subjects with inadequate vitamin D status, the daily consumption of milk was on average $<300 \mathrm{~g} / \mathrm{d}$ and the intake of spreads and fish was lower than among subjects of similar age with adequate vitamin D levels. On the basis of the FINDIET 2007 survey, the highest vitamin $\mathrm{D}$ intake was found among persons over 55 years of age due to their higher fish intake ${ }^{(19)}$.

Based on other studies vitamin D intake is still not adequate among young children and men ${ }^{(20-22)}$. In addition, the recommendation on vitamin $\mathrm{D}$ intake may be too low, and it has been suggested that it should be increased $^{(23)}$. Consequently, the National Nutrition Board has recently established an expert group to safeguard adequate vitamin $\mathrm{D}$ intake in the population. In theory, the most effective and safest fortification programme would include all potentially fortifiable foods fortified with vitamin $\mathrm{D}$ at level $1 \cdot 2-1 \cdot 5 \mu \mathrm{g} / 418 \mathrm{~kJ}(100 \mathrm{kcal})^{(24)}$. This would set the intake of the whole adult population between the currently recommended intake of $7 \cdot 5 \mu \mathrm{g} / \mathrm{d}$ and the currently tolerable upper intake level of $50 \mu \mathrm{g} / \mathrm{d}$.

\section{Labelling the salt content of foods}

The National Nutrition Council recommended the lowering of the salt intake level in the population as far back as 1978, but no recommended level was given until 1981, after the first survey in Eastern Finland had shown that salt intake was about $13 \mathrm{~g}$ in men and $11 \mathrm{~g}$ in women ${ }^{(25)}$. The recommended level was set at $\leq 9 \mathrm{~g}$. Gradually the recommended level has been decreased, being 7-9 $\mathrm{g}$ in $1987,7 \mathrm{~g}$ in $1994,0 \cdot 5 \mathrm{~g} / \mathrm{MJ}(3-5 \mathrm{~g} \mathrm{NaCl})$ in 1998, and most recently, in $2005,6 \mathrm{~g}$ in women and $7 \mathrm{~g}$ in men, the final long-term aim being $5 \mathrm{~g}^{(5)}$.

Salt intake in the Finnish population has been monitored regularly in the FINRISK and FINDIET surveys, both using the $24 \mathrm{~h}$ urinary sodium and the calculated dietary sodium intake ${ }^{(25,26)}$. Salt intake has decreased continuously to a level of about $9 \mathrm{~g}$ in men and $7 \mathrm{~g}$ in women in $2007^{(19)}$.

The decrease in salt intake has been the result of several actions: education of the public and health-care personnel, cooperation with the food industry, as well as national legislation concerning salt labelling. The national labelling decrees have been formulated by the Ministry of Trade and Commerce in close cooperation with the salt experts and food industry. The latest version was formulated in 2008, after the European Union (EU) had adopted its current regulation on nutrition and health claims, thereby forcing Finland to change its national definition of low-salt products.

As a consequence, the term low-salt was changed to reduced salt, and food items having reduced salt content status must have $25 \%$ less salt than normally salted products.

Moreover, the salt content of the most important dietary sources of salt such as bread, cheese, sausages and other meat products, soups and sauces, and prepared and semiprepared foods, are required to declare their salt content on their labels. The criteria for reduced salt content as well as for the heavily salted products have been revised. For example, fresh bread can be labelled as having a reduced salt content if it is $0.9 \mathrm{~g} / 100 \mathrm{~g}$ or less, and bread that has more than $1 \cdot 2 \mathrm{~g} / 100 \mathrm{~g}$ salt must be labelled as heavily salted. This labelling has been a very useful tool for consumers to identify products with reduced salt content, and it has made the food industry reformulate the content of their products, since the label 'heavily salted' is not particularly popular. We have carried out an analysis showing the potential impact of this labelling, making calculations based on the assumption that all consumers would buy available products with reduced salt content ${ }^{(27)}$. The results showed that salt labelling could be a useful component in an overall strategy to reduce the salt intake in the population.

\section{Fortification of salt by iodine}

Goitre was a considerable public health problem in the early 1900s. Iodine prophylaxis was suggested in the 1930s and implemented in the late 1940s. The concentration of iodine in salt was increased gradually and has been about $25 \mathrm{mg} / \mathrm{kg}$ salt since the early 1960s. The proportion of iodized salt of all table salt increased from about 10-20\% in the 1950 s to close to $90 \%$ in the late 1960 s. However, the food industry still does not use iodized salt. Iodine has also been added to cattle feed to increase productivity. Thus, in the 1960s, the occurrence of endemic goitre in the younger generations decreased and goitre was no longer considered a problem in Finland ${ }^{(28)}$.

Because of the iodized fodder, the iodine content of all animal foods, mainly milk products and eggs, increased and, actually, made a bigger contribution to iodine intake than iodized table salt ${ }^{(30)}$. Estimated intake of iodine, 
according to dietary studies, increased from the late $1950 \mathrm{~s}$, from about $60 \mu \mathrm{g} / \mathrm{d}$ to close to $300 \mu \mathrm{g} / \mathrm{d}$ by the end of the 1970s. It has, however, decreased since then. The daily recommended intake is $150 \mu \mathrm{g}$. The calculated iodine intake is now about $300 \mu \mathrm{g}$ in men and $240 \mu \mathrm{g}$ in women ${ }^{(28)}$. The main dietary sources of iodine are salt, liquid milk products and cheese. Comparisons between iodine intake with the $24 \mathrm{~h}$ excretion of iodine showed, however, that the calculations based on $100 \%$ iodized salt overestimate the intake by about $30 \%$, since the food industry does not generally use iodized salt. Currently, the iodine status of the population is adequate, but needs to be monitored. Roughly, only about $30 \%$ of all salt is iodized and as the main sources of iodine are milk products, cheese and salt, the iodine intake may be low in population groups with low consumption levels of milk, cheese and salt.

\section{The challenges facing nutrition policy}

Nutrition policy in Finland is increasingly influenced by the EU. EU policies such as the Common Agricultural Policy and the Consumer Protection strategy influence the supply and demand of food and thus have a crucial influence on nutrition and public health policies of member states ${ }^{(29)}$. Food legislation is highly harmonized within the community, and some national regulations that have been overrun by EU rules have been better from a nutritional viewpoint. However, food and nutrition are slowly rising onto the EU's political agenda because of the burden caused by nutritionrelated non-communicable diseases and premature death. The European Commission has, since May 2007, adopted a strategy to improve dietary habits in the $\mathrm{EU}^{(30)}$, and common strategies discussed in this document such as the EU's salt reduction initiative also influence the national food and nutrition policy.

One of the strengths of Finland's nutrition policy lies in the extensive knowledge of nutrition problems and the reasons behind them. Regular monitoring systems as well as a long tradition of epidemiological studies are the cornerstones of this knowledge base. The National Nutrition Council intermittently updates its nutrition recommendations for a healthy population, and other groups of specialists have given specific recommendations for different age groups, to aid the prevention and treatment of nutrition-related illnesses, as well as to improve mass catering. The authorities, organizations and industry work together. Mass catering, supported by society, gives people good examples of how to compose a balanced meal. The availability of healthy food options has been improved, for instance, by national legislation, and consumers are interested in improving their health by making conscious lifestyle choices.

Although much has been achieved, some public health problems have not been solved. Obesity and diabetes have become the most threatening nutrition-related illnesses, and osteoporosis is increasing. CVD has not yet been overcome, and more work is needed to combat them.

The central problem in Finnish nutrition policy is that the authorities have not often taken proposed fiscal measures seriously, and the responsibility for solving the problem has been left too much to consumers. Finland's nutrition policy can be regarded as weak compared to the country's agricultural or economic policies. For example, it has been repeatedly proposed that the value-added tax (VAT) on fruit and vegetables should be lower than the VAT on other foods, but these proposals have been ignored. Fiscal measures could and should be used to lower the price of healthy foods and to increase the price of unhealthy foods such as sugary beverages and sweets as well as products with high-saturated fat content. This measure has finally been proposed by the present government.

The key tool used in Finnish nutrition policy has been to teach consumers basic knowledge and skills regarding nutrition, as a part of their basic education. Society has the responsibility to enable consumers to lead a healthy lifestyle by making decisions that support the goals of nutritional policy. Furthermore, ministries should place more importance on nutrition policy. The measures put forward by the National Nutrition Council, and the government resolution on development guidelines for healthenhancing physical activity and nutrition, should be included in political decision-making, including at the level of local government in the municipalities. Such goals should be dealt with alongside the goals of economic, industrial, regional and agricultural policy. Implementation of the measures should also be monitored.

\section{References}

1. Valtioneuvoston kanslia (2007) Hallituksen strategia-asiakirja (In Finnish, summary in English). Valtioneuvoston kanslian julkaisusarja 18/2007. http://www.vn.fi/toiminta/ politiikkaohjelmat/terveys/ohjelman-sisaeltoe/en.pdf (accessed March 2010)

2. Ministry of Social Affairs and Health (2008) Government resolution on development guidelines for health-enhancing physical activity and nutrition. Brochures 2008:10eng. http://www.stm.fi/julkaisut/esitteita-sarja/nayta/_julkaisu/ 1069549\#en (accessed March 2010).

3. Ministry of Social Affairs and Health (2008) Press release 239/2008, published 17.8.2008. http://www.stm.fi/tiedotteet/ tiedote/view/1263125 (accessed March 2010).

4. Ministry of Social Affairs and Health (2008) National action plan to reduce health inequalities 2008-2011. Publications of the Ministry of Social Affairs and Health 2008:25. http:// pre20090115.stm.fi/pr1227003636140/passthru.pdf (accessed March 2010).

5. National Nutrition Council (2005) Suomalaiset Ravitsemussuositukset (In Finnish, title in English: Finnish Nutrition Recommendations - Diet and Physical Activity in Balance). Committee Report. Helsinki: Edita Publishing Oy; available at http://www.evira.fi/portal/vrn/en/nutrition_ recommendations/

6. Nordic Council of Ministers (2005) Nordic Nutrition Recommendations: Integrating Nutrition and Physical 
Activity, 4th ed. Scanprint as, Århus: Nordic Council of Ministers Nord 2004:13

7. Roos E \& Prättälä R (1997) Meal pattern and nutrient intake among adult Finns. Appetite 29, 11-24.

8. Prättälä R \& Raulio S (2006) Eating outside home. In Nutrition in Finland, pp. 21-22. [P Pietinen, L Etu-Seppälä, $\mathrm{S}$ Koskinen et al., editors]. Painoprisma Oy, Helsinki: Publications of the National Public Health Institute.

9. Raulio S, Roos E \& Prättälä R (2010) School and workplace meals - Do they promote healthy food habits in the population? Public Health Nutr (in this issue).

10. Hoppu U, Lehtisalo J, Tapanainen H et al. (2010) Dietary habits and nutrient intake of Finnish adolescents. Public Health Nutr (in this issue).

11. Raulio S, Roos E, Mukala K et al. (2007) Can working conditions explain differences in eating patterns during working hours? Public Health Nutr 11, 258-270.

12. World Health Organization (2003) Diet, Nutrition and the Prevention of Chronic Diseases. Joint FAO/WHO Expert Consultation. WHO Technical Report Series no. 916. Geneva: WHO.

13. Meltzer HM, Fotland TØ, Alexander J et al. (2008) Risk Assessment of Caffeine among Children and Adolescents in the Nordic Countries. TemaNord. Copenhagen: Nordic Council of Ministers; available at http://norden.org/pub/ miljo/miljo/uk/TN2008551.pdf

14. Valsta L, Borg P, Heiskanen S et al. (2008) Beverages in Nutrition. Report of the National Nutrition Council of Finland; available at http://wwwb.mmm.fi/ravitsemusneuvottelukunta/ Beverages_in_nutrition_Summary_of_opinions.pdf

15. Alfthan G (2010) Nationwide supplementation of sodium selenate to commercial fertilizers. History and 20-year results from the Finnish selenium monitoring program. In Food based approaches (FBAs) for combating micronutrient deficiencies [L Amoroso and B Thompson, editors]. FAO Food and Agriculture Organization (In press).

16. Salonen JT, Alfthan G, Huttunen JK et al. (1982) Association between cardiovascular death and myocardial infarction and serum selenium in a matched-pair longitudinal study. Lancet 8291, 175-179.

17. Salonen JT, Alfthan G, Huttunen JK et al. (1984) Association between serum selenium and the risk of cancer. $A m J$ Epidemiol 120, 342-349.

18. Lamberg-Allardt C, Viljakainen H, Pietinen P et al. (2009) Extensive voluntary fortification of fluid milk products improve vitamin D status in consumers with an overall effect on vitamin D status in the whole population (Submitted).

19. Paturi M, Tapanainen H, Reinivuo H et al. (editors) (2008) The National FINDIET 2007 Survey (In Finnish, tables, figures and summary in English). Publications of the National Public Health Institute B23/2008. Helsinki: Yliopistopaino; available at http://www.ktl.fi/attachments/ suomi/julkaisut/julkaisusarja_b/2008/2008b23.pdf.

20. Laaksi IT, Ruohola J-PS, Ylikomi TJ et al. (2006) Vitamin D fortification as public health policy: significant improvement in vitamin D status in young Finnish men. Eur J Clin Nutr 60, 1035-1038.

21. Välimäki V-V, Löttyniemi E \& Välimäki MJ (2006) Vitamin D fortification of milk products does not resolve hypovitaminosis D in young Finnish men. Eur J Clin Nutr 61, 493-497.

22. Piirainen $\mathrm{T}$, Laitinen $\mathrm{K} \&$ Isolauri $\mathrm{E}$ (2007) Impact of national fortification of fluid milks and margarines with vitamin D on dietary intake and serum 25-hydroxyvitamin D concentration in 4-year-old children. Eur J Clin Nutr 61, 123-128.

23. Lamberg-Allardt C (2006) Vitamin D in foods and as supplements. Prog Biophys Mol Biol 92, 33-38.

24. Hirvonen T, Sinkko H, Valsta LM et al. (2007) Development of a model for optimal food fortification: vitamin D among adults in Finland. Eur J Clin Nutr 46, 264-270.

25. Laatikainen T, Pietinen P, Valsta LM et al. (2006) Sodium in the Finnish diet: I Trends in urinary sodium excretion among the adult population. Eur J Clin Nutr 8, 965-970.

26. Reinivuo H, Valsta LM, Laatikainen T et al. (2006) Sodium in the Finnish diet: II Trends in sodium intake based on dietary surveys and Food balance Sheets. Eur J Clin Nutr 60, 1160-1167.

27. Pietinen P, Valsta LM, Hirvonen T et al. (2008) Labelling the salt content of foods: a useful tool in reducing sodium intake in Finland. Publ Health Nutr 11, 335-340.

28. Valsta LM, Lamberg-Allardt C, Bordeaux P et al. (2009) Iodine status of middle-aged subjects in Finland (Submitted).

29. Schäefer L, Lock K \& Blenkus G (2006) Public health, food and agriculture policy in EU. In Health in All Policies, pp. 93-110. [T Ståhl, M Wismar, E Ollila et al., editors]. Helsinki: Ministry of Social Affairs and Health.

30. White paper on a strategy for Europe on nutrition, overweight and obesity related health issues. http:// ec.europa.eu/health/ph_determinants/life_style/nutrition/ documents/nutrition_wp_en.pdf (accessed March 2010). 